
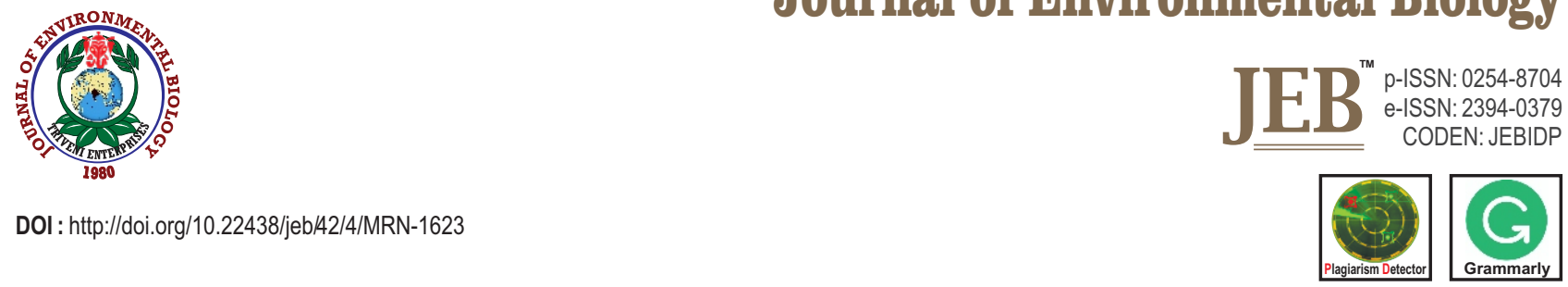

\title{
An in-vitro study of Himalayan plant extracts against oomycetes disease Saprolegniasis in rainbow trout (Oncorhynchus mykiss)
}

\author{
R.S. Tandel ${ }^{1,2 *}$, N.K. Chadha', P. Dash ${ }^{1,2}$, P.B. Sawant', N.N. Pandey', S. Chandra', R.A.H. Bhat ${ }^{1,2}$ and D. Thakuaria ${ }^{2}$ \\ 'ICAR-Central Institute of Fisheries Education, Mumbai-400 036, India \\ ${ }^{2}$ ICAR-Directorate of Coldwater Fisheries Research, Nainital-263 136, India \\ *Corresponding Author Email : ritesh.tandel@icar.gov.in
}

\section{Abstract}

Aim: This study aimed to investigate the effectiveness of ethanolic extract of three Himalayan plants Myrica esculenta, Thymus linearis and Butea monosperma on hyphal germination, colonisation and sporulation of two species of Saprolegnia (Saprolegnia parasitica and S. australis) isolated from rainbow trout, Oncorhynchus mykiss. Molecular docking of active ingredients of M. esculenta, Myricetin with effector proteins of S. parasitica was also performed to investigate the target binding sites for drug development.

Methodology: Minimum inhibitory concentration (MIC), mycelium growth inhibition, spore germination, and inhibition was performed with the most effective concentrations. Molecular docking was carried out with AutoDock Vina software to investigate target binding sites with S. parasitica.

Results: Extracts from Myrica esculenta, Thymus linearis and Butea monosperma showed MIC values of the $25,100,50 \mathrm{mg} \mathrm{m}^{-1}$ against $S$. parasitica and $25,50,25 \mathrm{mg} \mathrm{ml}^{-1}$ against $S$. australis hyphal growth, respectively. Nevertheless, malachite green as reference control was effective with a MIC value of $2.5 \mathrm{mg} \mathrm{l}^{-1}$. The concentration required to inhibit $S$. parasitica and $S$. australis spores were (50) Myrica esculenta, (25) Thymus linearis, (100) Butea monosperma in $\mathrm{mg} \mathrm{ml}^{-1}$ and (50) Myrica esculenta, (50) Thymus linearis, (100) Butea monosperma in $\mathrm{mg} \mathrm{ml}^{-1}$, respectively.

Interpretation: The study concludes that $M$. esculenta and B. monosperma are effective against $S$ aprolegniasis and could be used as phyto additives.

Key words: Anti-oomycetes, Plant extract, Saprolegnia australis, Saprolegnia parasitica, Spore germination

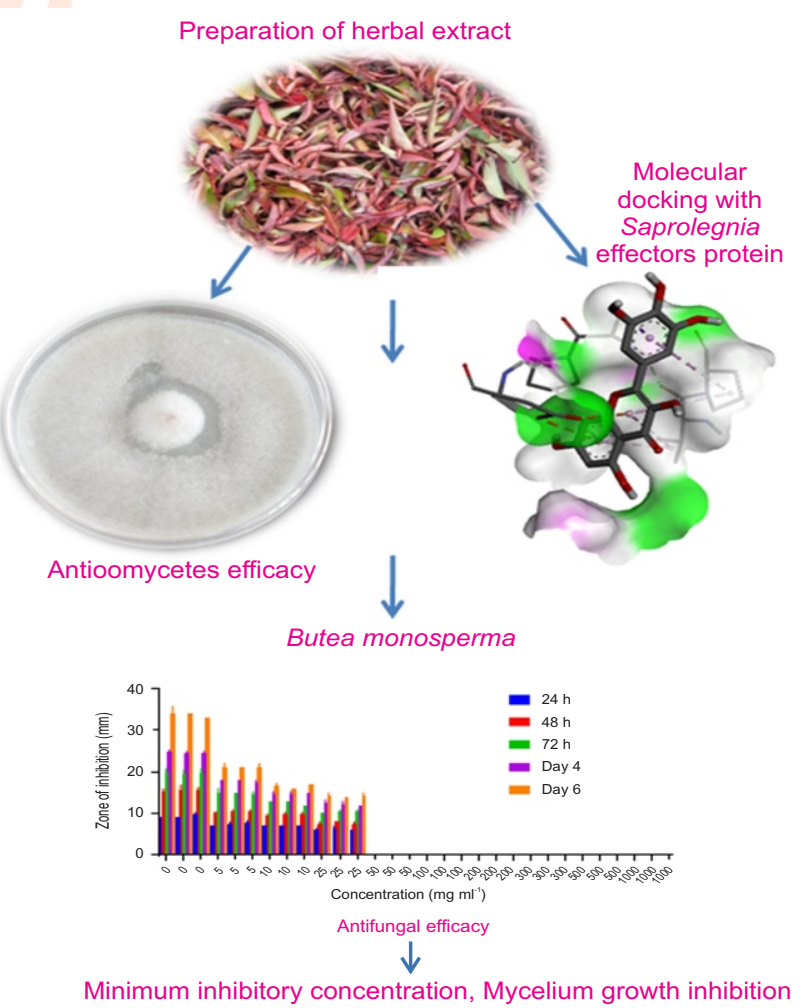

How to cite : Tandel, R.S., N.K. Chadha, P. Dash, P.B. Sawant, N. Pandey, S. Chandra, R.A.H. Bhat and D. Thakuaria: An in vitro study of Himalayan plant extracts against oomycetes disease Saprolegniasis in rainbow trout (Oncorhynchus mykiss). J. Environ. Biol., 42, 1008-1018 (2021). 


\section{Introduction}

Trout farming has progressed steadily in India, and in the last 15 years, the cold water aquaculture industry has developed tremendously in states and union territory of Jammu \& Kashmir, Himachal Pradesh, Sikkim, Uttarakhand and Arunachal Pradesh (Singh, 2020). Intensification of culture practices, climate changes, and genetically fatigue stock are the major bottlenecks for expanding trout farming in India (Barat et al., 2015). In trout farming, major diseases are caused by bacteria, virus, parasites and water moulds (oomycetes). Fungal and fungal-like, oomycetes infections are second only to bacterial disease outbreaks resulting in economic losses in aquaculture (van West, 2006). Saprolegniasis is one of the most severe diseases encountered in rainbow trout, Oncorhynchus mykiss farming (Tandel et al., 2020a). Saprolegniales are responsible for the weakening of immune mechanism and death of fishes causing economic losses in salmonids and other aquaculture industries (Masigol et al., 2019; Tandel et al., 2020b). Saprolegniasis is characterised by white or grey cotton-like patches/hyphae on the skin and fins of infected fish (Das et al., 2012). Among several strains of Saprolegnia, Saprolegnia parasitica, S. australis and S. diclina are responsible for significant infections in fish and eggs, particularly in aquaculture facilities (van Den Berg et al., 2013).

Previously, Saprolegnia infection was effectively controlled by malachite green. However, since 2002, the use of malachite green has been banned worldwide due to its carcinogenic and toxicological effects. Formalin, copper sulphate, hydrogen peroxide, boric acid, ozone, iodophor, sodium chloride and peracetic acid are reported as other antifungal agents to control the saprolegniasis in the eggs of salmonids (Ali et al., 2017; Tedesco et al., 2019). Nevertheless, there are no chemicals presently available that give sufficient protection against the disease after hatching (Srivastava et al., 2018; Good et al., 2020). Hyphal infection is particularly devastating in aquaculture hatcheries and can spread quickly between neighbouring eggs (Smith et al., 1985). At present, extra attention needs to be taken care of the oomycetes infections at early stages of rainbow trout.

One of the substitutions of these synthetic compounds is the use of natural plant extracts or purified compounds of herbal compounds, which are locally available, abundant, low cost, low residual effects and can be used in large aquaculture ponds (Huang et al., 2015). In many countries, raditional herbal medicines are used to prevent diseases in humans as well as in animals (Sharma et al., 2010). Dichloromethane extract from red seaweed Ceramium rubrum elicited antimicrobial activity against S. parasitica (Cortes et al., 2014). Magnolia officianalis and Euphorbia fischeriana demonstrated antifungal activity against Saprolegnia sp. isolated from the tail skin of infected grass carp, Ctenopharyngodon idella (Huang et al., 2015). Caruana et al. (2012) also documented the growth dynamics of S. australis by plant extracts of Rumex obtusifolius, Sophora flavescens, Echinacea and Zingiber officinalis.
In the present study, the effectiveness of plant extracts of M. esculenta, T. linearis and B. monosperma was tested against different life stages of Saprolegnia spp. isolated from farms and hatcheries of rainbow trout, O. mykiss. Molecular docking of active ingredients of $M$. esculenta with effector proteins of $S$. parasitica was also carried out to investigate the target binding sites for drug development.

\section{Materials and Methods}

Saprolegnia spp. isolate: Pure culture of S. parasitica and S. australis, isolated previously from oomycetes affected rainbow trout, Oncorhynchus mykiss were used in the efficacy study. Radial growth edges of pure culture isolates were excised into uniformed sizes $(5 \times 5 \mathrm{~mm})$ and placed onto the middle of Potato Dextrose Agar (PDA) plates supplemented with antibiotics (250 $\mathrm{mg} \mathrm{I}^{-1}$ ampicillin, Invitrogen). Hemp seeds and sesame seeds were provided as bait. Seed with hyphal attachments was taken and washed 2-3 times in sterilised distilled water and transferred into PD broth for $48 \mathrm{hrs}$ and then sterilised tap water in $90 \mathrm{~mm}$ petri plates (Axygen) to observe zoospore formation.

Collection of plants and extract preparation: The collected plant parts such as leaves of $M$. esculenta, T. linearis and flowers of $T$. linearis were adequately washed 2-3 times with tap water and soaked in distilled water for $30 \mathrm{~min}$ to remove the dust. They were dried in shade for 5 days and then ground to powder form. The ethanolic extract was prepared by dissolving $2.8 \mathrm{~g}$ of dried sample in $35 \mathrm{ml}$ of $70 \%$ ethanol and kept in a shaker for $48 \mathrm{hrs}$ at $30^{\circ} \mathrm{C}$ for proper mixing of the sample. After that, the mixture was filtered through Whatman filter paper (No.1), and the remaining supernatant was centrifuged at $2460 \mathrm{rpm}$ for $10 \mathrm{~min}$. The supernatant was then evaporated at $40^{\circ} \mathrm{C}$ in a rotary evaporator. The plant extracts were collected and kept at $-20^{\circ} \mathrm{C}$ until further use for efficacy study. Malachite green (Himedia) was used as a reference control for efficacy study.

Anti-oomycetes efficacy tests: Different concentrations of plant extracts were prepared and added to sterilised PDA agar supplemented in $90 \mathrm{~mm}$ petri-plates with antibiotics (250 $\mathrm{mg} \mathrm{I}^{-1}$ ampicillin, Invitrogen) in triplicate and one as the control without herbal extract and malachite green at $2.5 \mathrm{mg} \mathrm{l}^{-1}$ as reference control. Following overnight solidification, hyphae from the advancing edge of growing colony of pure culture were cut and placed onto prepared PDA plates and incubated at $20 \pm 1^{\circ} \mathrm{C}$ and checked after $72 \mathrm{hr}$. The experiment was done three times, and the results were recorded visually for the presence of mycelium.

Minimum inhibitory concentration tests: Plant extracts showing negative mycelium growth were tested for minimum inhibitory concentration (MIC). The mixture with different concentrations was distributed in $90 \mathrm{~mm}$ petri-plates in triplicate and one without extract served as control, while malachite green as a reference control. Following overnight solidification, hyphae from the advancing edge of the growing colony of pure culture were cut and placed onto prepared plates and incubated at $20 \pm 1^{\circ} \mathrm{C}$ and checked routinely for 
$24 \mathrm{hr}, 48 \mathrm{hr}$ and $72 \mathrm{hr}, 96 \mathrm{hr}$ and $144 \mathrm{hr}$, respectively. The experiment was replicated three times, and the lowest concentration inhibiting the growth of the mycelium after 6 days of incubation was taken as minimum inhibitory concentrations.

Mycelium growth inhibition assay: In-vitro oomycetes activity of the plant extracts were assessed. For the mycelium growth inhibition assay, the radial growth of mycelium was measured for each plate after $24 \mathrm{hr}, 48 \mathrm{hr}, 72 \mathrm{hr}, 96 \mathrm{hr}$ and $144 \mathrm{hr}$.

Spore germination inhibition and colonisation test: The hyphae of Saprolegnia isolates grown on PDA plates were excised and incubated in PD broth at $20^{\circ} \mathrm{C}$ for two days to obtain the fungal mat. The newly grown mats were repeatedly washed three to four times in autoclaved tap water and incubated at $20^{\circ} \mathrm{C}$ for $15 \mathrm{hr}$. Zoospores number in autoclave tape water (ATW) were counted using a Neubauer hemocytometer and expressed as spores $\mathrm{ml}^{-1} .400$ microliter of Saprolegnia spore suspension $\left(1 \times 10^{5}\right.$ spore $\left.\mathrm{ml}^{-1}\right)$ and $400 \mu \mathrm{l}$ of each tested drug concentration were incubated with hemp seed in 24 well flat-bottom plates at $20^{\circ} \mathrm{C}$. Sterilised distilled water was used as a non-treated control, and malachite green was used as a positive control. After 24,48 and $72 \mathrm{hrs}$, the plates were examined microscopically (Nikon eclipse, Japan).

Molecular docking of myricetin with S. parasitica functional and virulent proteins: V-type proton ATPase structures of $S$. parasitica were not available in the PDB bank. So the homology modelling of $S$. parasitica catalytic protein was performed using alignment mode of SWISS-MODEL server (https:// swissmodel. expasy.org). The software aligns the submitted amino acid sequence with the known templates available in the protein data bank. Based on the degree of similarity, the target templates were selected, and the model was built for all the protein sequences. In the Blast $P$, the desired template was not present for $S$. parasitica host targeting protein. Thus, for developing 3D structure of $S$. parasitica host targeting protein, BLAST-PDB search was initiated to identify potential templates with a default matrix of BLOSUM62. The template with better score listed by pDOMTHREADER was considered for homology modelling using Modeller 9.18 stand alone version.

The modelled 3D structures were refined using Mod Refiner (https://zhanglab.ccmb.med.umich.edu/ModRefiner/). To verify these properties RAMPAGE and Procheck servers were used to locate the unique geometry of each residue in all the 3D models. Myricetin ligand 12 were downloaded from Pubchem and converted into PDB coordinate files by using OPENBABEL software. The ligands were virtually screened on the basis of Lipinski's "rule of five" that sets criteria for drug-like properties (Lipinski et al., 2004). The binding sites of each protein were predicted by 3D Ligand stie. The AutoDock Vina software was used to simulate the ligand into active site of protein to calculate the binding energy of ligand-receptor complexes. Computerbased docking predicted nine docking poses for each ligandprotein complex. The preferable binding orientation between protein and compound, with more negative binding affinity score, was considered for further study (Meng et al., 2011). The threedimensional structures and $2 \mathrm{D}$ docking interactions were visualised using discovery studio visualiser.

Statistical analyses: Minimum inhibitory concentration (MIC), mycelium growth inhibition and spore germination inhibition (SGI) were performed in triplicate and results were expressed as mean value $\pm S$.E. Statistic at analyses were done with Graph Pad Prism 8.4.2 (Graph Pad Software, San Diego, USA). Graph Pad Prism 8.4.2 were also used to plot the graph of MIS and SGI. Non-linear regression and sigmoid curve were fitted (see Troskie et al., 2012) with $95 \%$ confidence intervals and below equation

$$
Y=\text { Bottom }+(\text { Top-Bottom }) /\left(1+10^{\wedge}((\text { LoglC50-X)*HillSlope }))\right.
$$

Top represent high antioomycetes activity and bottom denotes growth as in control. $\mathrm{IC}_{50}$ represents $50 \%$ growth inhibition than control. One way ANOVA with multiple comparison test was used for statistical analysis of three biological repeats with triplicate technical repeats for comparison of $\mathrm{I}_{50}$.

\section{Results and Discussion}

Malachite green, n-methylated diaminodiphenylmethane has been restricted since 2002, as fungicides or ectoparasiticide because of its mutagenicity, teratogenicity and carcinogenicity (Srivastava et al., 2004). Moreover, available chemical treatments and approved formulations like formalin and hydrogen peroxide pose a high risk to humans as well as wildlife and carcinogenic in nature (European Commission, 2014), which are likely to be banned shortly. Therefore, efforts are being made to identify safe and effective alternative antimycotic agents to control oomycetes, Saprolegnia pathogens in different life stages of fishes like eggs and adults (Ali et al., 2019).

In this study, in-vitro screening of plant extracts available in Indian Himalayan regions having reported antifungal activity were performed against Saprolegnia spp. isolated from 0 . mykiss. The antioomycetes activity were performed following the protocols of Huang et al. (2015), Madrid et al. (2015) and Tedesco et al. (2019). Plant extracts of M. esculenta, T. linearis and $B$. monosperma showed inhibitory effects on the hyphae growth with MIC values of $25,100,50 \mathrm{mg} \mathrm{ml}^{-1}$ against $S$. parasitica and $25,50,25 \mathrm{mg} \mathrm{ml}^{-1}$ against $S$. australis, respectively (Fig. 1). At the same time, MIC value for positive reference control malachite green were $2.5 \mathrm{mg} \mathrm{l}^{-1}$. Several plant extracts have been reported as anti-oomycetes agent. Rumex obtusifolius, Sophora flavescens, Echinacea and Zingiber officinale screened out of twenty-four crude plant extracts were effective against Saprolegnia australis isolated from brown trout (Caruana et al., 2012). Petroleum ether extracts of Aucklandia lappa, Cnidium monnieri and Magnolia officinalis were effective against Achlya klebsiana, and Saprolegnia sp. infection (Xue-Gang et al., 2013). Similarly, Huang et al. (2015), evaluated the effectiveness of thirty naturally occurring plant species against Saprolegnia sp. from 


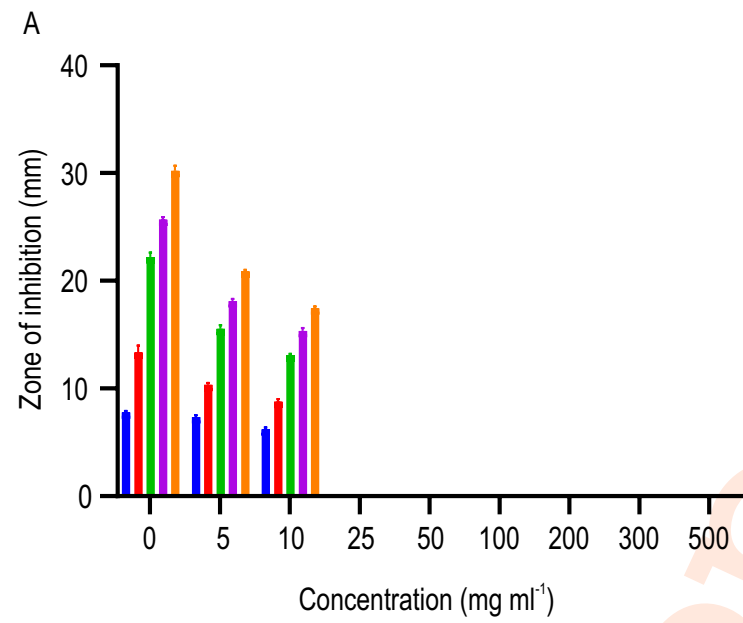

B
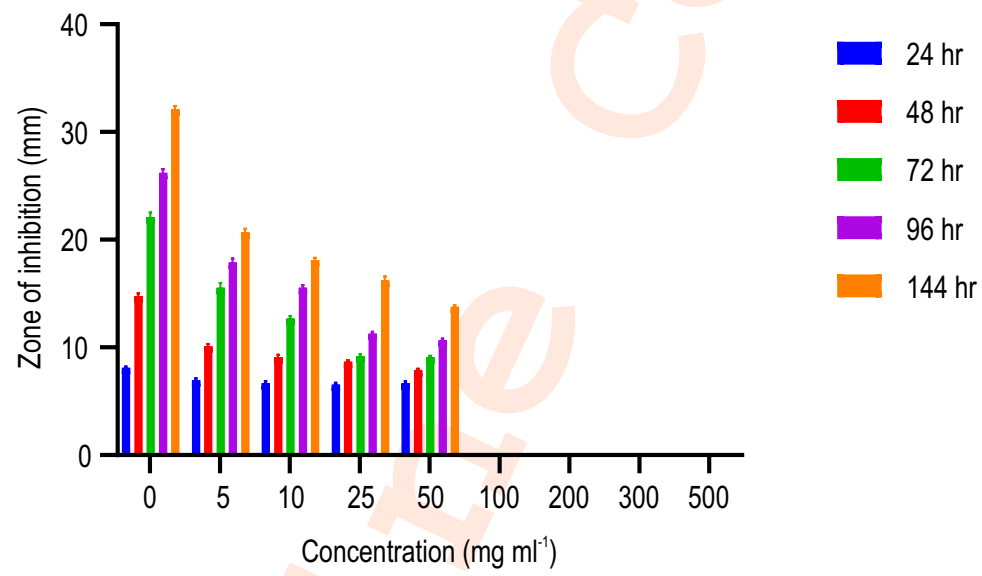

C

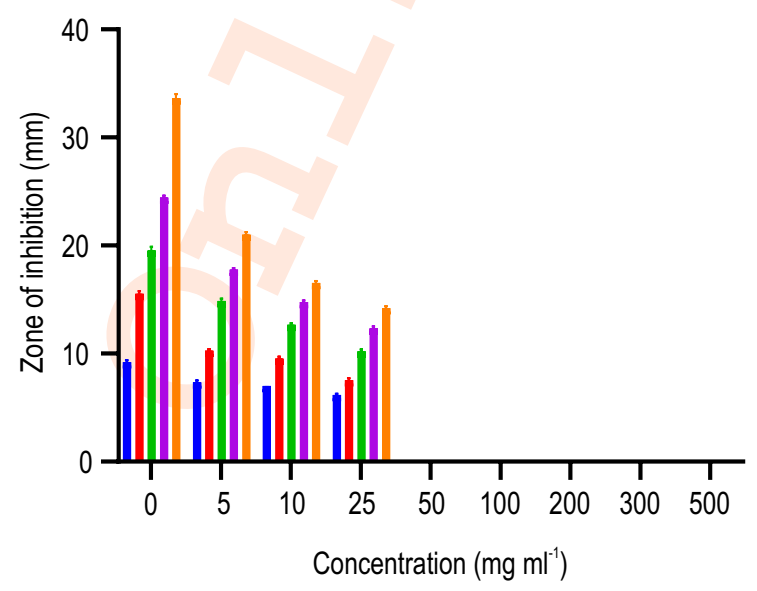

$24 \mathrm{hr}$

$48 \mathrm{hr}$

$72 \mathrm{hr}$

$96 \mathrm{hr}$

$144 \mathrm{hr}$

Fig. 1: Minimum inhibitory concentration (zone of inhibition) of three plant extract against S. parasitica) M. esculenta against S. parasitica; B.) T. Linearis against S. parasitica; C.) B. monosperma against S. parasitica; The growth of both Saprolegnia sp. were evaluated over $24 \mathrm{hr}, 48 \mathrm{hr}, 72 \mathrm{hr}, 96 \mathrm{hr}$ and 144 $\mathrm{hr}$. Each growth measurement is mean of triplicates \pm S.E. 
D
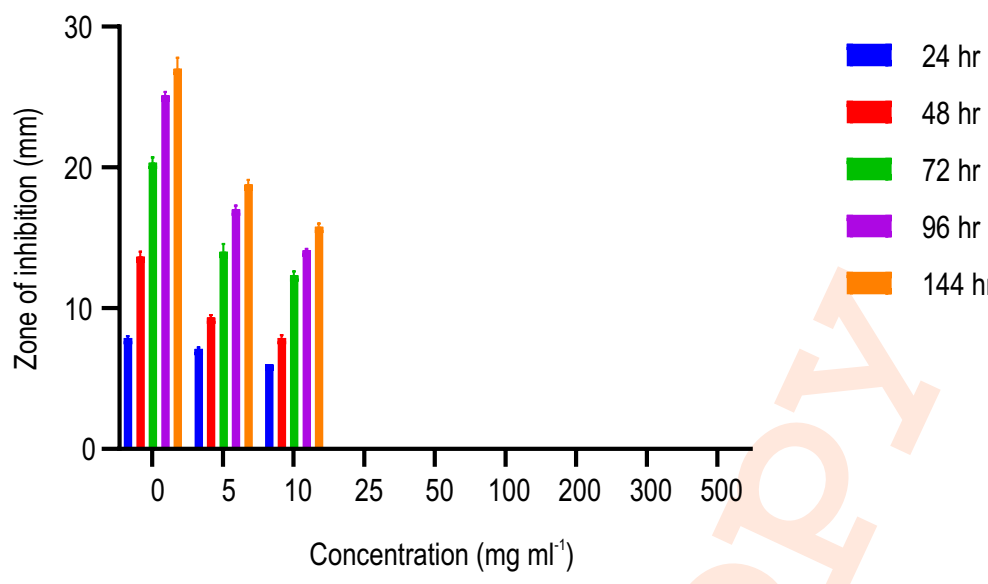

E

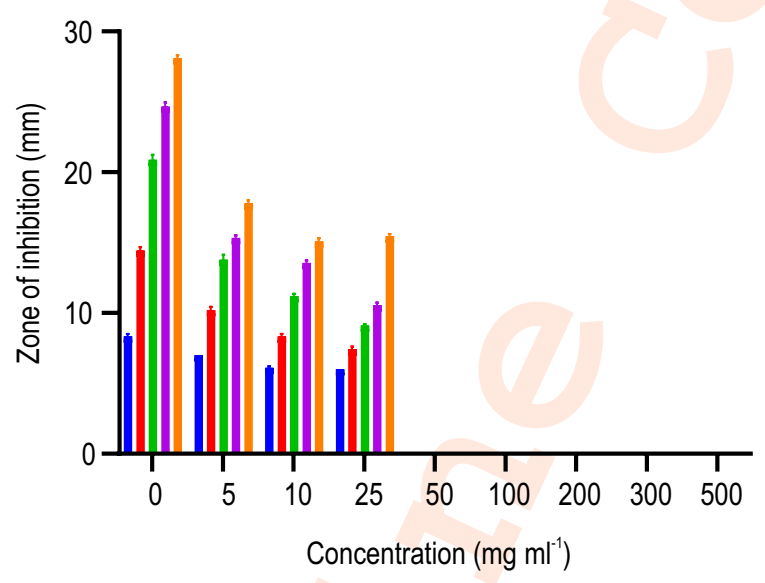

$24 \mathrm{hr}$
$48 \mathrm{hr}$
$72 \mathrm{hr}$
$96 \mathrm{hr}$
$144 \mathrm{hr}$

$\mathrm{F}$

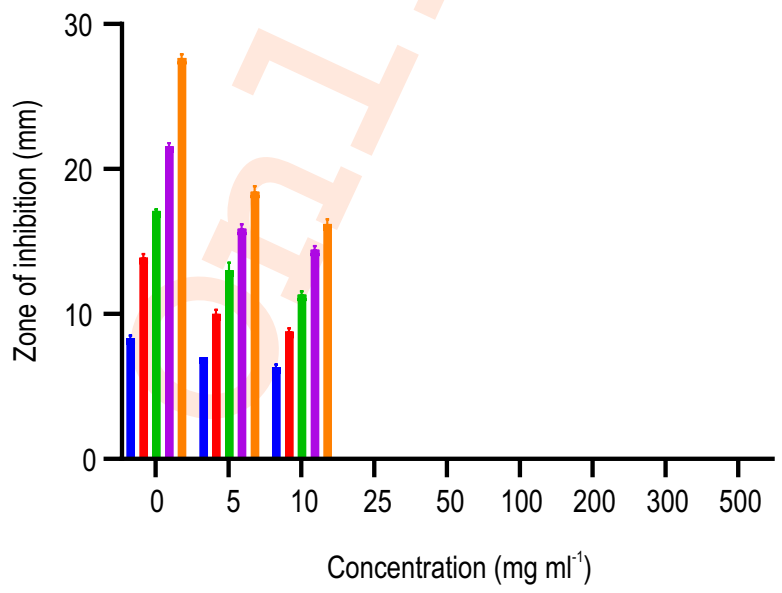

Fig. 1: Minimum inhibitory concentration (zone of inhibition) of three plant extract against S. australis. D.) M. esculenta against S. australis; E.) T. Linearis against S. australis; F.) B. monosperma against S australis. The growth of both Saprolegnia sp. were evaluated over $24 \mathrm{hr}, 48 \mathrm{hr}, 72 \mathrm{hr}, 96 \mathrm{hr}$ and $144 \mathrm{hr}$. Each growth measurement is mean of triplicates \pm S.E. 
A

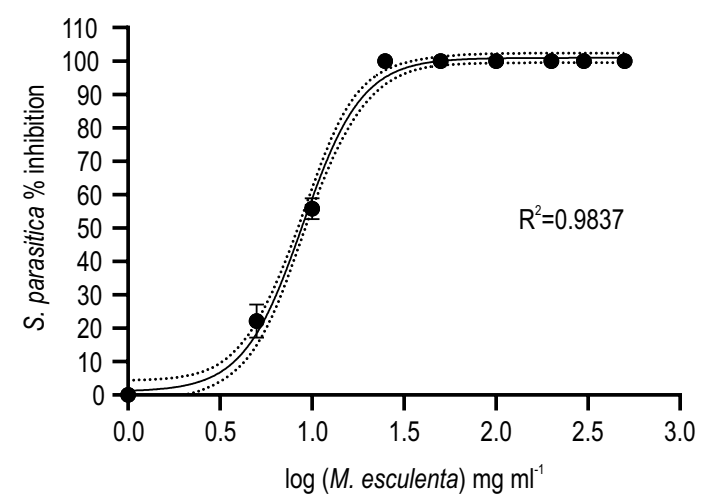

B

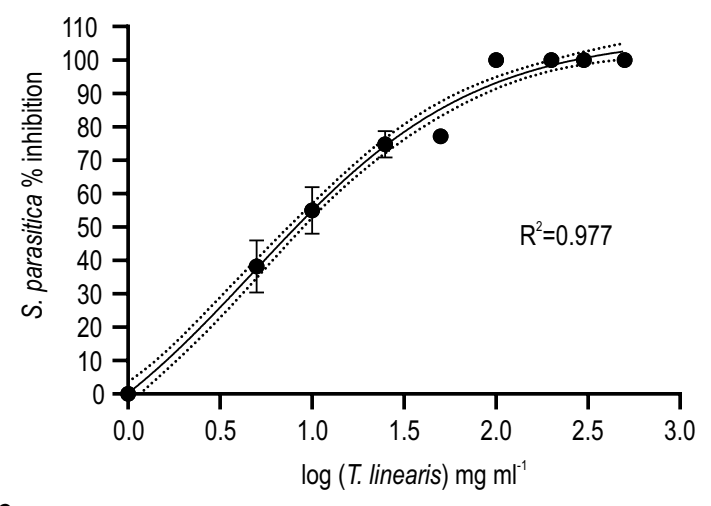

C

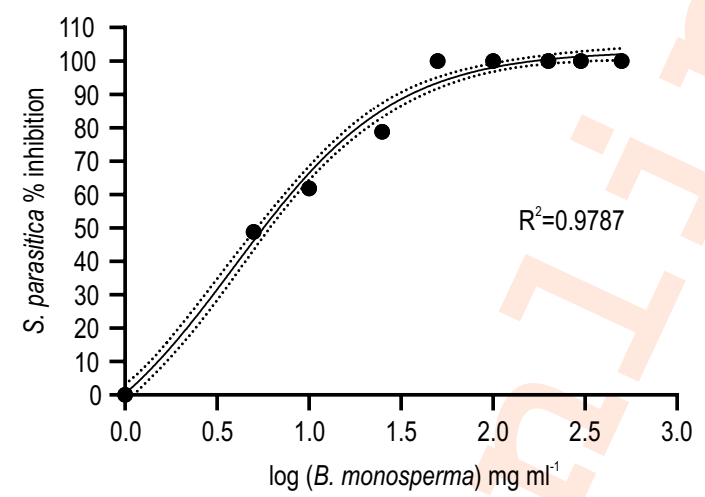

D

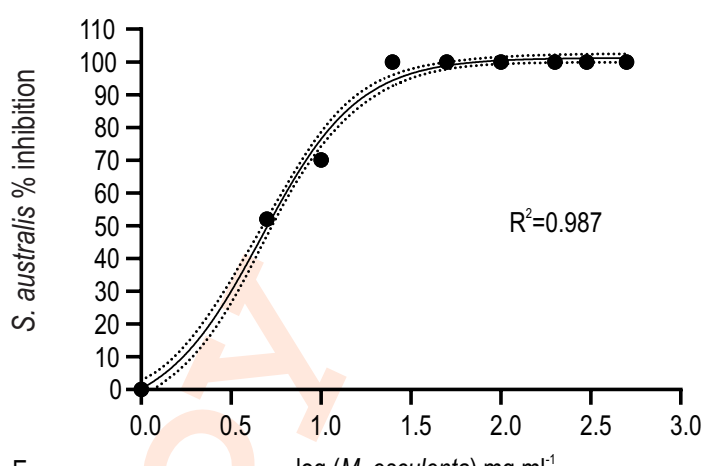

E $\log$ (M. esculenta) $\mathrm{mg} \mathrm{m}^{-1}$
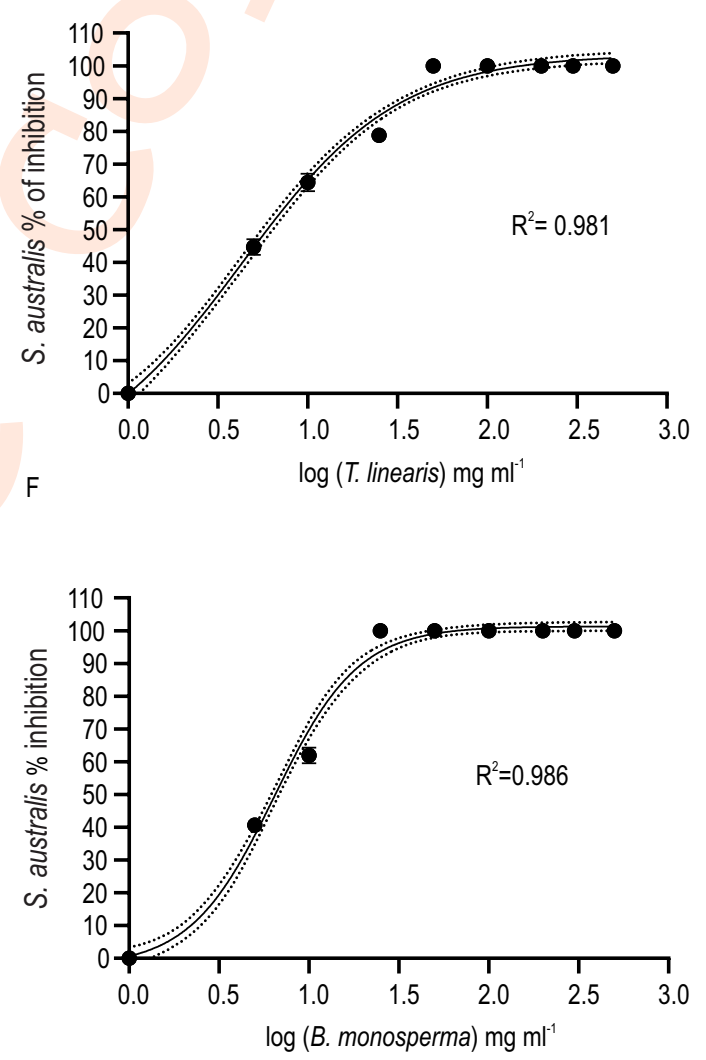

Fig. 2: Mycelium growth inhibition, SGI representative \% inhibition response curve of plant extract against S. parasitica and S. australis; A.) M. esculenta against S. parasitica; B.) T. Linearis against S. parasitica; C.) B. monosperma against S. parasitica; D.) M. esculenta against S. australis; E.) T. Linearis against $S$ australis; F.) B. monosperma against $S$ australis. The dotted line represents the prediction interval value at $95 \%$ confidence for the sigmoidal line fit of data.

cultured grass carp (Ctenopharyngodon idella) and found that Magnolia officinalis and Euphorbia fischeriana had antimycotic activity. Cao et al. (2014) reported S. australis infection from Carassius gibelio eggs and suggested Radix sanguisorbae extracts as potential anti-Saprolegnia agents. Existing synthetic compounds and treatment regimes against Saprolegnia infections are limited, uneconomical in large volume ponds, environmental restrictions, having teratogenicity or carcinogenicity and insufficient to constraints losses in aquaculture. Use of phytoadditives as an alternative approach attracts a great deal of attention due to their local availability, effectiveness, low toxicity, environmentally safe and low costs (Lieke et al., 2020). However, 

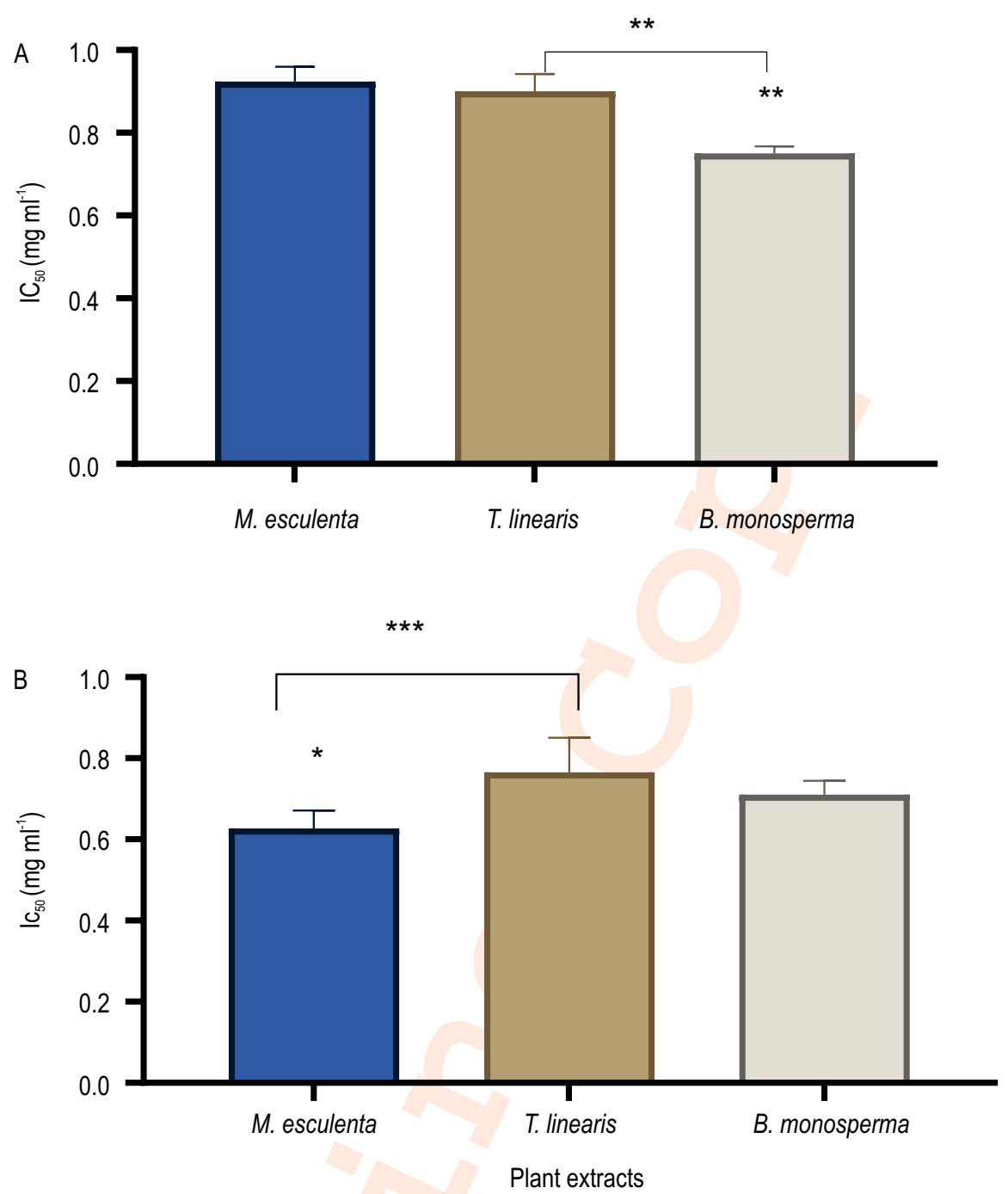

Fig. 3: Comparision $I C_{50}$ value of $M$. esculenta, T. linearis and B. monosperma against $S$. parasitica $(A)$ and $S$. australis (B).

literature on the effect of sporulation, germination and colonisation of different Saprolegnia species isolated from rainbow trout, 0 . mykiss is scarce. Furthermore, anti-oomycetes activity of Himalayan plants has been tested with respect to different life stages of oomycetes, for the first time in this study. The extracts of $T$. linearis and $M$. esculenta exhibited inhibition of spore germination in $S$. parasitica and $S$. australis.

The concentration required to inhibit $S$. parasitica and $S$. australis spores were (50) Myrica esculenta, (25) Thymus linearis, (100) Butea monosperma in $\mathrm{mg} \mathrm{ml}^{-1}$ and (50) Myrica esculenta, (50) Thymus linearis, (100) Butea monosperma in mg $\mathrm{ml}^{-1}$, respectively. The spore germination inhibition test was performed according to Ali et al. (2014). An oomycetes reproduces as swimming zoospores asexually, when reaches a potential host (fish,eggs), it encysts and germinate by producing hyphal growth to develop Saprolegniasis in fish (Paria et al., 2020). $I C_{50}$ value at which $50 \%$ growth inhibition of $S$. parasitica and $S$. australis was attained by extracts of $M$. esculenta, $T$. linearis and B. monospermais depicted in Fig. 2 and 3. A significant difference was observed in $\mathrm{IC}_{50}$ value of $T$. linearis (0.8 $\left.\mathrm{mg} \mathrm{ml}^{-1}\right)$ and $B$. monosperma $\left(0.7 \mathrm{mg} \mathrm{ml}^{-1}\right)$ against $S$. parasitica and $M$. esculenta $\left(0.6 \mathrm{mg} \mathrm{m}^{-1}\right)$ and $T$. linearis $\left(0.7 \mathrm{mg} \mathrm{ml}^{-1}\right)$ against S. australis (Fig. 3). Myrica esculenta, widely distributed in Kumaun and Garhwal region of Uttarakhand and Himalaya possesses medicinal properties like antimicrobial, antiinflammatory and antioxidant activities (Shah et al., 2010; Bhandari et al., 2019). Antifungal activity of M. esculenta was reported against Aspergillus niger and Candida albicans due to arylheptanoid myricanone and other bioactive compounds such as saponins, oleanolic acid, p-coumaric acid, and orstigmasterol (Kabra et al., 2019). Similarly, antifungal activity of T. linearis 
A

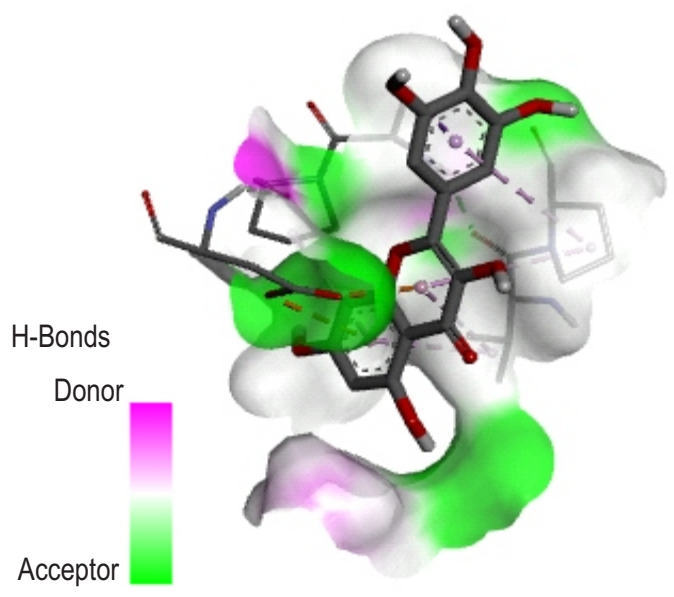

B

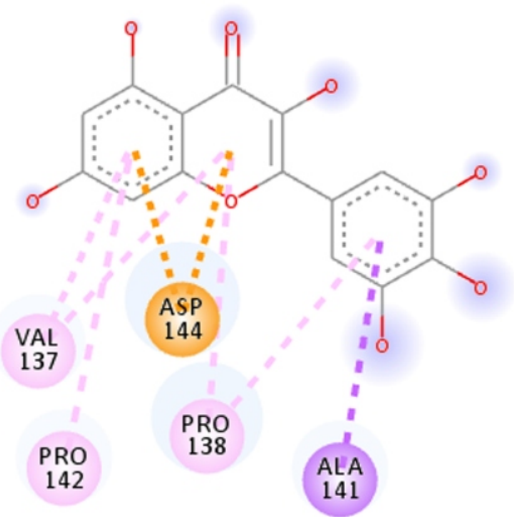

Interactions

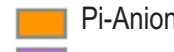

Pi-Sigma
Pi-Alkyl

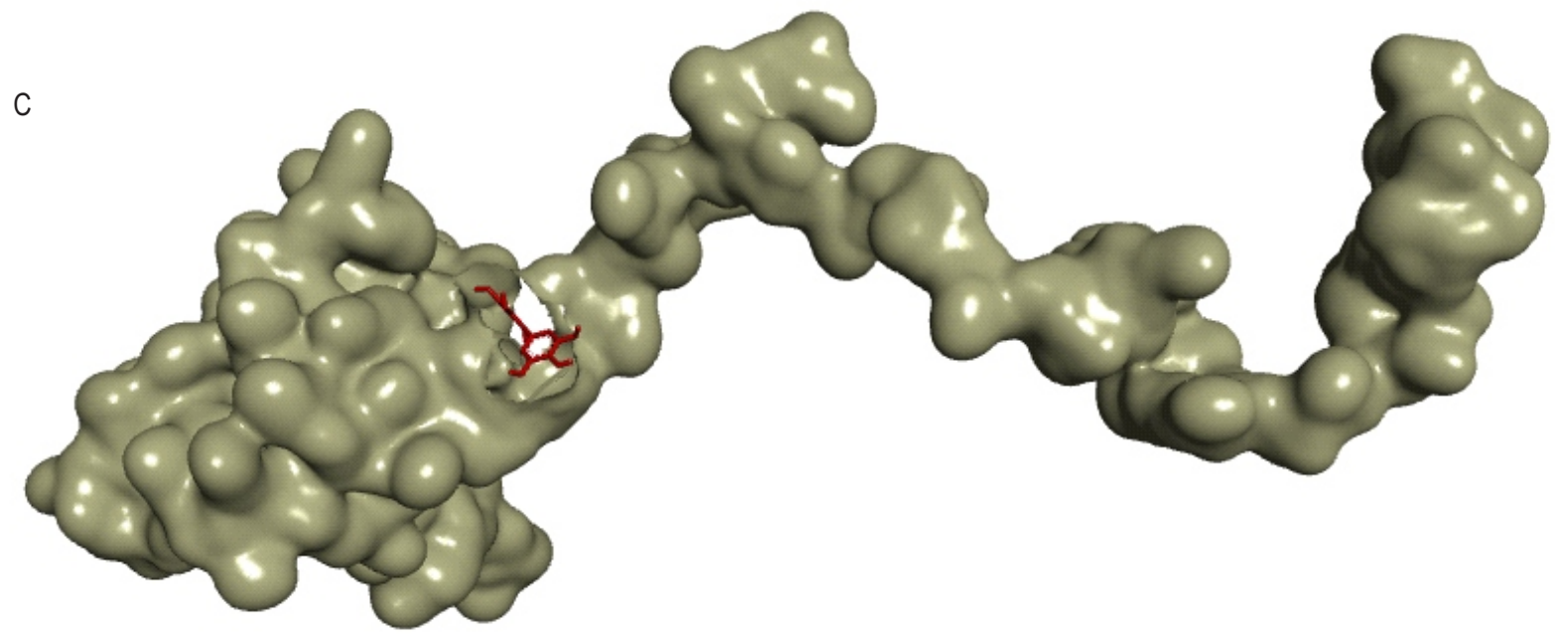

Fig. 4: $2 D(A-B)$ and $3 D(C)$ presentation of docked $H$ bonds on the active sites of host targeting protein of S. parasitica with myricetin.

(Shah et al., 2019) and T. vulgaris were reported against $C$. albicans (Gedikoglu et al., 2019). Therapeutic importance of $B$. monosperma mainly includes the treatment of inflammation, diabetes, worm and skin infection (Das and Smita, 2018). Although, the antifungal activity of $B$. monosperma has been reported against $A$. niger (Singh , 2011).

The detailed 2D and 3D interactions between the active sites of S. parasitica proteins and myricetin (Bhat et al., 2020a), an phytochemical compounds present in $M$. esculenta are given in Fig. 4 and 5. The molecular docking result showed better binding affinities with $S$. parasitica $\mathrm{htp}^{-1}$ and $\mathrm{V}$ type proton kinase with the binding energy of -5.1 and $-6.8 \mathrm{Kcal} \mathrm{mol}^{-1}$, respectively. Besides several hydrophobic interactions, two conventional hydrogen bonds were reported between the $\mathrm{V}$ type proton kinase and myricetin, thus followed the Lipinski's "rule of five (Lipinski et al.,
2004; Bhat et al., 2020b). There are around 969 proteins responsible for virulence of Saprolegnia (Jiang et al., 2013), among these V-Type Proton ATPase and host targeting protein has crucial role for the virulence of oomycetes species through vacuolar, and cytoplasmic pH homeostasis (Hayek et al., 2014; Srivastava et al., 2018).

The docking results revealed that, the strong molecular docking interaction of myricetin with V-type ATPase which indicates the inhibitory virulence of $S$. parasitica may act as a potent anti-oomycetes agent. In another study, the myricetin forms 11 hydrogen bonds and showed inhibitory activity against Aeromonas hydrophila (Bhat et al., 2020a). With regards to antioomycetes activity of myricetin, no previous reports are available to collaborate our study. The results were consistent with in vitro studies, possibly due to its inhibitory activity and decrease 

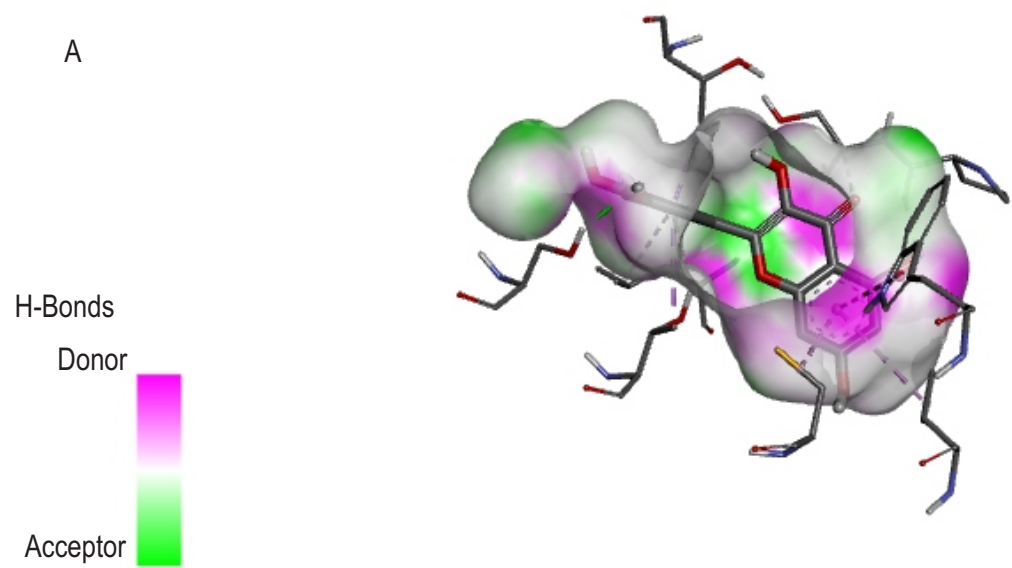

B

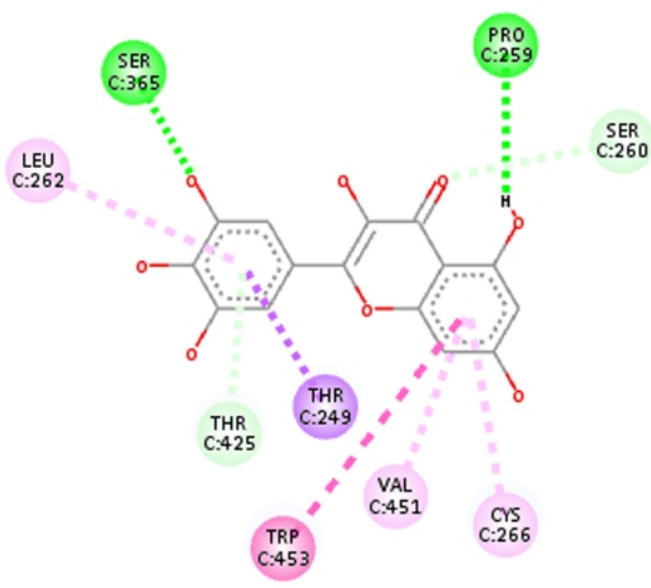

Interactions

Conventional Hydrogen Bond Carbon Hydrogen Bond Pi-Donor Hydrogen Bond

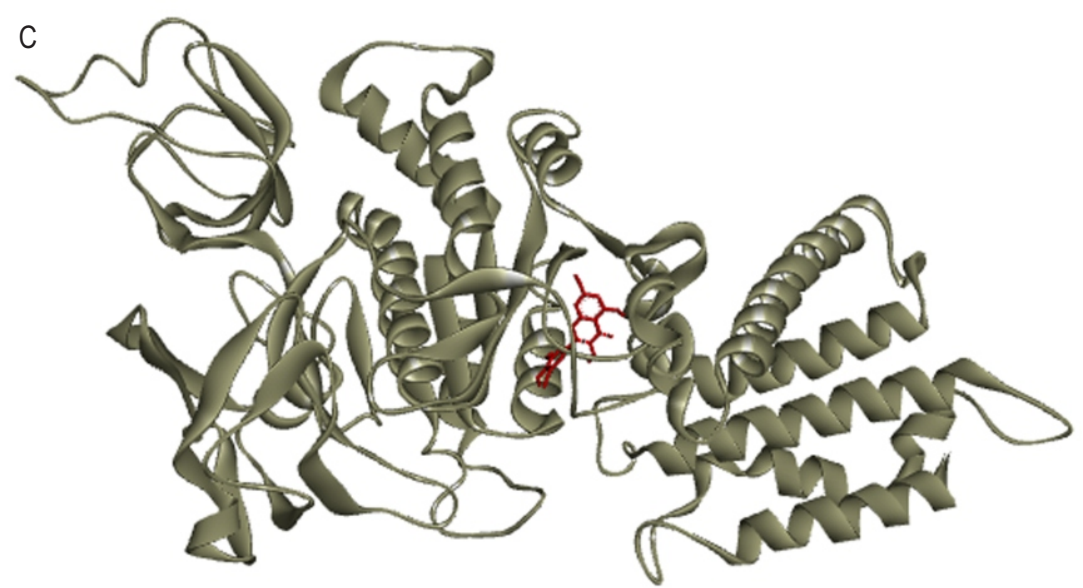

Fig. 5: 2D (A-B) and 3D (C) presentation of docked $\mathrm{H}$ bonds on the active sites of $\mathrm{V}$ type protein kinase of S. parasitica with myricetin. 
virulence of $S$. parasitica. The present investigation concludes that the ethanolic extract of $M$. esculenta, $T$. linearis and $B$. monosperma showed anti-oomycetes activity against $S$. parasitica and $S$. australis pathogen under in-vitro conditions. The anti-oomycetes action was due to inhibition of hyphal growth and spore germination of Saprolegnia pathogen. The binding prediction of $M$. esculenta with target proteins demonstrated that it has more specificity towards the Htp site and TKL protein kinase of $S$. parasitica. This study will enable us to develop a safe antioomycetes agent for effective control of different life stages of Saprolegnia spp. in rainbow trout farming. In final note, further research is needed on safety and efficacy of use of M. esculenta, $T$. linearis, $B$. monosperma extract and its compound with respect to different life stages of fish, and these plant extract can be used as a potent anti-oomycetes agent in aquaculture.

\section{Acknowledgments}

This work was carried out under the project funding of AQ 20 (3) of Indian Council of Agricultural Research and part of Ph.D research work of first author. The authors duly acknowledge the Director, ICAR Directorate of Coldwater Fisheries Research, Bhimtal and Director, ICAR Central Institute of Fisheries Education, Mumbai, for providing necessary facilities.

\section{Add-on Information}

Authors' contribution: R.S. Tandel: Conceptualization, Methodology; N. K. Chadha: Project Administration; P. Dash, R.A.H. Bhat: Data curation, Editing \& reviewing; P B Sawant, N.N. Pandey, S. Chandra, D. Thakuaria: Supervision.

Research content: The research content of manuscript is original and has not been published elsewhere.

Ethical approval: All applicable international, national, and/or institutional guidelines were followed (Institutional Animal Ethics Committee of ICAR-DCFR/Ref. No. IAEC/44(127)/2008/DC/ 3842-48) for sampling, maintenance, handling during experiments.

Conflict of interest: No conflict of interest was reported by the author(s).

Data from other sources: The supplement data generated during and analysed during the current study are available from the corresponding author on reasonable request.

Consent to publish: All authors agree to publish the paper in Journal of Environmental Biology.

\section{References}

Ali, S.E. and I. Skaar: A fluorescence-based assay for in vitro screening of Saprolegnia inhibitors. J. Fish Dis., 40, 1333-1339 (2017).
Ali, S.E., A.A. Gamil, I. Skaar, Ø. Evensen and H. Charo-Karisa: Efficacy and safety of boric acid as a preventive treatment against Saprolegnia infection in Nile tilapia (Oreochromis niloticus). Sci. Rep., 9, 1-9 (2019).

Ali, S.E., E. Thoen, $\varnothing$. Evensen and I. Skaar: Boric acid inhibits germination and colonisation of Saprolegnia spores in vitro and in vivo. PLoS ONE, 9, e91878 (2014).

Bhat, R.A.H., S. Rehman, R.S. Tandel, P. Dash, A. Bhandari, P.A. Ganie, T.K. Shah, K. Pant, D.J. Yousuf, I.A. Bhat and S. Chandra: Immunomodulatory and antimicrobial potential of ethanolic extract of Himalayan Myrica esculanta in Oncorhynchus mykiss: Molecular modelling with Aeromonas hydrophila functional proteins. Aquaculture, 533, 736213(2020a).

Bhat, R.A.H., D. Thakuria, V. Pant, V.C. Khangembam, R.S. Tandel, N. Shahi, D. Sarma, G. Tripathi, K.K. Krishnani and G. Krishna: Antibacterial and anti-oomycete activities of a novel designed RY12WY peptide against fish pathogens. Micro. Pathoge., 149, 104-591 (2020b).

Barat, A., P.K. Sahoo, R. Kumar, J.I. Mir, S. Ali, R.S. Patiyal and A.K. Singh: Molecular characterisation of rainbow trout, Oncorhynchus mykiss (Walbaum, 1792) stocks in India. J. Genet., 94, 13-18 (2015).

Bhandari, A., R.A.H. Bhat, R.S. Tandel, P. Dash, T.K. Shah, P.A. Ganie, and D. Sarma: Investigation of acute toxicity and behavioural changes on Oncorhynchus mykiss, rainbow trout fry in response to ethanolic extract of Myrica esculenta. Phar. Inno. J., 8, 807-810 (2019).

Cao, H., R. Ou, G. Li, X. Yang, W. Zheng and L. Lu: Saprolegnia australis RF Elliott 1968 infection in Prussian carp Carassius gibelio (Bloch, 1782) eggs and its control with herb extracts. J. Appl. Ichthyol., 30, 145-150 (2014).

Caruana, S., G.H. Yoon, M.A. Freeman, J.A. Mackie and A.P. Shinn: The efficacy of selected plant extracts and bioflavonoids in controlling infections of Saprolegnia australis (Saprolegniales; Oomycetes). Aquaculture, 358, 146-154 (2012).

Cortés, Y., E. Hormazábal, H. Leal, A. Urzúa, A. Mutis, L. Parra and A. Quiroz: Novel antimicrobial activity of a dichloromethane extract obtained from red seaweed Ceramium rubrum (Hudson) (Rhodophyta: Florideophyceae) against Yersinia ruckeri and Saprolegnia parasitica, agents that cause diseases in salmonids. Electron. J. Biotechnol., 17, 126-131 (2014).

Das, M. and S. Smita: Biosynthesis of silver nanoparticles using bark extracts of Butea monosperma (Lam.) Taub. and study of their antimicrobial activity. Appl. Nanosci., 8, 1059-1067 (2018).

Das, S.K., K. Murmu, A. Das, I. Shakuntala, R.K. Das, S.V. Ngachan and S.K. Majhi: Studies on the identification and control of pathogen Saprolegnia in selected Indian major carp fingerlings at mid hill altitude. J. Environ. Biol., 33, 545-549 (2012).

European Commission: Technical Guidance Document on risk Assessment, Part I (2014).

Gedikoğlu, A., M. Sökmen and A. Çivit: Evaluation of Thymus vulgaris and Thymbra spicata essential oils and plant extracts for chemical composition, antioxidant, and antimicrobial properties. Food Sci. Nutr., 7, 1704-1714 (2019).

Good, C., J. Davidson, D.L. Straus, S. Harper, D. Marancik, T. Welch, B. Peterson, L.F. Pedersen, C. Lepine, N. Redman and T. Meinelt: Assessing peracetic acid for controlling post vaccination Saprolegnia spp. associated mortality in juvenile Atlantic salmon Salmo salar in freshwater recirculation aquaculture systems. Aquacul. Resh., 51, 2624-2627 (2020).

Hayek, S.R., S.A. Lee and K.J. Parra: Advances in targeting the vacuolar proton-translocating ATPase (V-ATPase) for anti-fungal therapy. Front. Pharmacol., 5, p. 4 (2014). 
Huang, X.L., R.J. Liu, S. Whyte, Z.J. Du, D.F. Chen, Y.Q. Deng, K.Y. Wang and $Y$. Geng: The in vitro antifungal activity of 30 Chinese herb extracts to Saprolegnia sp. J. Appl. Ichthyol., 31, 681-686 (2015).

Jiang, R.H., I. de Bruijn, B.J. Haas, R. Belmonte, L. Löbach, J. Christie, G. van den Ackerveken, A. Bottin, V. Bulone, S.M. Díaz-Moreno and B. Dumas: Distinctive expansion of potential virulence genes in the genome of the oomycete fish pathogen Saprolegnia parasitica. PLoS Genet., 9, e1003272 (2013).

Kabra, A., R. Sharma, C. Hano, R. Kabra, N. Martins and U.S. Baghel: Phytochemical composition, antioxidant, and antimicrobial attributes of different solvent extracts from Myrica esculenta Buch.-Ham. ex. D. Don leaves. Biomolecules, 9, 357 (2019).

Lieke, T., T. Meinelt, S.H. Hoseinifar, B. Pan, D.L. Straus and C.E Steinberg: Sustainable aquaculture requires environmental friendly treatment strategies for fish diseases. Rev. Aquac., 12, 943-965 (2020).

Lipinski, C.A.: Lead-and drug-like compounds: The rule-of-five revolution. Drug Disco. Today Technol., 1, 337-341, (2004).

Madrid, A., P. Godoy, S. González, L. Zaror, A. Moller, E. Werner, M. Cuellar, J. Villena and I. Montenegro: Chemical characterization and anti-oomycete activity of Laureliopsis philippianna essential oils against Saprolegnia parasitica and S. australis. Molecules, 20, 8033-8047 (2015).

Masigol, H., S.A. Khodaparast, J.N. Woodhouse, K. RojasJimenez, J. Fonvielle, F. Rezakhani and H.P. Grossart: The contrasting roles of aquatic fungi and oomycetes in the degradation and transformation of polymeric organic matter. Limnol. Oceanog., 64, 2662-2678 (2019).

Meng, X.Y., H.X. Zhang, M. Mezei and M. Cui: Molecular docking: A powerful approach for structure-based drug discovery. Curr. Comput. Aided Drug Des., 7, 146-157 (2011).

Paria, A., A.K. Dev, P.K. Pradhan, R. Kumar, G. Rathore and N. Sood: Evaluation of therapeutic potential of selected antifungal chemicals and drugs against Aphanomyces invadans. Aquaculture, 529, 735643 (2020).

Shah, T.K., A. Kumar, R.S. Tandel, A. Bhat and D.Sarma: Identification of functional groups in Thymus linearis ethanol leaf extract through fourier transform infrared spectroscopy (FTIR). J. Pharmoco. Phyoche., 8, 3013-3015(2019).

Shah, S., A. Tewari, B. Tewari and R.P. Singh: Seed maturity indicators in Myrica esculenta, Buch-Ham. Ex. D. Don: A multipurpose tree species of subtropical-temperate Himalayan region. New Forest., 40, 9-18 (2010).

Sharma, A., A.D. Deo, S.T. Riteshkumar, T.I. Chanu and A. Das: Effect of
Withania somnifera (L. Dunal) root as a feed additive on immunological parameters and disease resistance to Aeromonas hydrophila in Labeo rohita (Hamilton) fingerlings. Fish Shellfish Immunol., 29, 508-512 (2010).

Singh, A.K.: Emerging scope, technological up-scaling, challenges and governance of rainbow trout Oncorhynchus mykiss (Walbaum, 1792) production in Himalayan region. Aquaculture, 518, 734826 (2020).

Singh, V.: Therapeutic importance of Butea monosperma: A review. J. Drug Deliv. Ther., 1, (2011).

Smith, S.N., R.A. Armstrong, J. Springate and G. Barker: Infection and colonisation of trout eggs by Saprolegniaceae. Trans. Br. Mycol. Soc., 85, 719-723(1985).

Srivastava, V., S. Rezinciuc and V. Bulone: Quantitative proteomic analysis of four developmental stages of Saprolegnia parasitica. Front. Microbiol., 8, 2658 (2018)

Srivastava, S., R. Sinha and D. Roy: Toxicological effects of malachite green. Aquat. Toxicol., 66, 319-329 (2004).

Tandel, R.S., P. Dash and R.A.H. Bhat: Emerging oomycetes infections in coldwater fishes. In: Coldwater Fisheries and Aquaculture (Eds.: D. Sarma and N. Shahi). Narendra Publishing House, India, p. 101 (2020a)

Tandel, R.S., P. Dash, R.A.H. Bhat, P. Sharma, K. Kalingapuram, M. Dubey and D. Sarma: Morphological and molecular characterization of Saprolegnia spp. from Himalayan snow trout, Schizothorax richardsonii: A case study report. Aquaculture, 531, 735824 (2020b)

Tedesco, P., M.L. Fioravanti and R. Galuppi: In vitro activity of chemicals and commercial products against Saprolegnia parasitica and Saprolegnia delica strains. J. Fish Dis., 42, 237-248 (2019).

Troskie, A.M., N.M. Vlok and M. Rautenbach: A novel 96-well gel-based assay for determining antifungal activity against filamentous fungi. J. Microbiol. Methods, 91, 551-558 (2012).

Van Den Berg, A.H., D. McLaggan, J. Diéguez-Uribeondo and P. Van West: The impact of the water moulds Saprolegnia diclina and Saprolegnia parasitica on natural ecosystems and the aquaculture industry. Fungal Biol. Rev., 27, 33-42 (2013).

Van West, P.: Saprolegnia parasitica, an oomycete pathogen with a fishy appetite: New challenges for an old problem. Mycologist, 20, 99104 (2006)

Xue-Gang, H., L. Lei, C. Cheng, H. Kun, Y. Xian-Le and W. Gao-Xue: In vitro screening of Chinese medicinal plants for antifungal activity against Saprolegnia sp. and Achlya klebsiana. North American J. Aquacult., 75, 468-473 (2013). 